\title{
Spiritual well-being and quality of life are impaired in chronic urticaria
}

\author{
Sérgio Dortas $\mathrm{Jr}^{1}$, Guilherme Azizi ${ }^{1}$, Rafael Moret $^{1}$, Rossy Bastos Junior ${ }^{1}$, and Solange \\ Valle $^{1}$ \\ ${ }^{1}$ Universidade Federal do Rio de Janeiro Hospital Universitário Clementino Fraga Filho
}

September 21, 2020

\begin{abstract}
Background: Patients with chronic urticaria (CU) often report an impaired quality of life (QoL). Although a positive effect of addressing spirituality in health care has been proved in several chronic diseases, its potential role in CU has received no attention. This study evaluated spirituality and QoL in CU subjects with different control levels. Methods: In a single-centre observational study, 100 CU subjects were investigated using Functional Assessment of Chronic Illness Therapy-Spiritual WellBeing (FACIT-Sp-12) scale, Chronic Urticaria Quality of life Questionnaire (CU-Q2oL) and Urticaria Control Test (UCT). Results: Of 100 subjects, 82 were female and 18 were male. It was observed that subjects with not controlled CU presented FACIT Sp-12 meaning/peace $(\mathrm{p}=0.004)$ significantly lower, and CU-Q2oL $(\mathrm{p}<0.0001)$ significantly higher (worst QoL) than subjects with controlled CU. There was no difference in the FACIT Sp-12 faith $(\mathrm{p}=0.43)$ between groups. There was moderate direct correlation between FACIT Sp-12 faith and FACIT Sp-12 meaning/peace $(\mathrm{r}=0.483 ; \mathrm{p}<0.0001 ; \mathrm{n}=100)$. There was a significant strong inverse correlation between the CU-Q2oL and the UCT $(\mathrm{r}=-0.762 ; \mathrm{p}<0.0001 ; \mathrm{n}=100)$. No correlation was found between the FACIT Sp-12 faith and CU-Q2oL, neither with UCT. Conclusion: No study has ever investigated the role of spirituality in managing patients with urticaria. Our findings support the impact of poorly controlled urticaria in spiritual well-being and QoL. Therefore, clinicians should pay more attention to spirituality among CU patients. We suggest that urticaria guidelines should include specific recommendations on spirituality assessment.
\end{abstract}

\section{Introduction:}

Chronic urticaria (CU) is a skin disorder in which red, swollen, itchy, and sometimes painful hives (wheals), angioedema, or both, repeatedly occur for more than 6 weeks. ${ }^{1}$ Prevalence is estimated up to $1 \%$ in the general population $^{2}$, with those aged between 30 and 50 years most affected, and females affected approximately twice as often as males. ${ }^{3-6}$ The current guidelines classify CU as spontaneous (chronic spontaneous urticaria [CSU], with no specified eliciting factor involved) or inducible (chronic inducible urticaria [CIndU], with a specific eliciting factor involved).1 Patients may concurrently experience CSU and CIndU in approximately $20 \%$ of cases. $^{4}$

Existing evidence indicates that symptoms of $\mathrm{CU}$ have a deleterious effect on the quality of life (QoL). ${ }^{2,7-9}$ It impacts daily activities and emotional well-being; some patients' health status is comparable to that of coronary artery disease and severe asthma patients. It also causes inconvenience in family structures, compromising performance at work, school, and negatively impacting on leisure activities. It compromises patients' QoL, mainly those with more severe disease or who are diagnosed with chronic spontaneous urticaria..$^{7,10}$ Until now there are no reliable biomarkers to identify and measure disease activity in CSU. Consequently, use of patient reported outcomes (PROs) is crucial when evaluating and monitoring different aspects of chronic urticaria such as disease activity/severity, disease control, and QoL. Five different PROs that measure various aspects of disease severity/activity and QoL are used routinely in research and clinical practice of chronic urticaria. Four of these PROs are urticaria-specific: weekly Urticaria Activity Score (UAS7); Urticaria Control 
Test (UCT); and Chronic Urticaria Quality of Life Questionnaire (CU-Q2oL); two are angioedema-specific: Angioedema Activity Score (AAS) and Angioedema Quality of Life Questionnaire (AE-QoL). ${ }^{11-15}$

Numerous other factors also may influence QoL. Among those likely to be important is spiritual well-being (SpWB). Viewed as a multifaceted construct, SpWB usually refers to a sense of meaning or purpose in life, inner peace and harmony, and the strength and comfort drawn from faith. ${ }^{16}$ SpWB has been measured over two dimensions (Meaning/Peace and Faith). Recent studies suggest a broad protective relationship between religious participation and population health. ${ }^{17}$ Although a positive effect of addressing spirituality in health care has been proved in several chronic diseases, spiritual well-being in patients with CU has never received attention.

The aim of this study was to evaluate spirituality and QoL in CU subjects with different control levels (subjects with controlled $\mathrm{CU}$ and those with not controlled $\mathrm{CU}$ ).

\section{Methods:}

Patients

We conducted a prospective single-centre observational study with 100 consecutive patients from the outpatient clinic of a Urticaria Center of Reference and Excellence (GA2 LEN UCARE, www. ga2len-ucare.com) ${ }^{18}$ at the Immunology Service of a university hospital. Patients were enrolled after informed consent was obtained. The study was submitted and approved by Comitê de Ética em Pesquisa do Hospital Universitário Clementino Fraga Filho (HUCFF-UFRJ), CAAE 45067715.5.0000.5257.

Measures

\section{Urticaria control assessment}

The UCT is a developed and validated instrument to determine the level of disease control in all forms of CU. It was originally developed in German and it has been validated to brazilian portuguese by our group. Two forms of the UCT are available: the long form UCT (UCTlg) (8 questions) and the short form UCT (UCTsh) (4 questions). Because the results of both UCT forms have been found to correlate extensively, the more convenient UCTsh is primarily used, both, in clinical trials and routine patient care. The categorizing recommendation is poorly controlled $\mathrm{CU}(\mathrm{UCT}<12)[\mathrm{n}=45]$ and well controlled CU (UCT [?] 12). ${ }^{12,15}$

\section{Spiritual Well-Being}

SpWB was measured using the Functional Assessment of Chronic Illness Therapy-Spiritual Well-Being (FACIT-Sp-12) Questionnaire. ${ }^{19-21}$ The FACIT-Sp-12 measures subjects' overall spiritual well-being and includes 2 subscales: meaning/peace and faith. The total score was obtained by summing all individual items (range, 0-44, with higher scores indicating greater spiritual well-being), and the subscale scores were obtained by summing all items in each domain. The meaning/peace subscale measures sense of meaning, peace and harmony, and purpose in life (range, 0-32). The faith subscale assesses the association between illness, faith, and spiritual beliefs as well as how one finds solace in one's faith (range, 0-16).

\section{Quality of Life}

Quality of life was measured using the CU-Q2oL. The CU-Q2oL is a CSU-specific health-related QoL questionnaire consisting of 23 questions. The questions cover different aspects of CSU's impact on patients' lives including pruritus, swelling, daily life activities, sleep, appearance, and limitations. CU-Q2oL scores range from 23 to 115, with a higher score indicating stronger impairment of health-related QoL. ${ }^{13,14}$

\section{Statistical Analysis}

First, to compare SpWB and QoL between the 2 groups (subjects with controlled CU and those with not controlled CU), univariate analyses were performed using a Mann-Whitney U test. Association between SpWB, QoL and disease control was assessed by Spearman's rank correlation coefficient. 
Nonparametric models were performed because the scores had a non-Gaussian distribution, according to the rejection of the hypothesis by the Shapiro-Wilk normality test. A $p$ value of $<0.05$ was regarded as statistically significant. All statistical analyses were performed using SAS(r) System statistical software, version 6.11 (SAS Institute, Inc., Cary, North Carolina).

\section{Results:}

\section{Subject Characteristics}

Of 100 subjects, 82 were female and 18 were male (mean +- standard deviation [SD] age, $43+-15$ years) [Table 1]. The characteristics of the subjects are summarized in Table 1.

\section{Score Characteristics}

Table 2 provides a description of the scores, in the total sample and by groups: poorly controlled $\mathrm{CU}$ [n $=$ $45]$ and well controlled $\mathrm{CU}[\mathrm{n}=55]$.

The scores did not present a normal distribution (Gaussian), according to the Shapiro-Wilk normality test, at the level of $5 \%$. Therefore, the most appropriate measures for summarizing the data were by quartiles (median, interquartile range (Q1 - Q3), minimum and maximum).

FACIT-Sp-12 Meaning/Peace, FACIT-Sp-12 Faith and CU-Q2oL between controlled and not controlled subjects

It was observed that subjects with not controlled CU presented FACIT Sp-12 meaning/peace $(\mathrm{p}=0.004)$ significantly lower, and CU-Q2oL $(\mathrm{p}<0.0001)$ significantly higher (worst QoL) than subjects with controlled CU. There was no difference in the FACIT Sp-12 faith $(\mathrm{p}=0.43)$ between the groups.

\section{FACIT-Sp-12 Meaning/Peace, FACIT-Sp-12 Faith, CU-Q2oL and UCT correlation}

There was moderate direct correlation between FACIT Sp-12 faith and FACIT Sp-12 meaning/peace $(\mathrm{r}=$ 0.483; $\mathrm{p}<0.0001)$.

Significant moderate inverse correlation was found between FACIT Sp-12 meaning/peace and CU-Q2oL (r $=-0.457 ; \mathrm{p}<0.0001)$.

FACIT Sp-12 meaning/peace correlated weak with UCT $(\mathrm{r}=0.331 ; \mathrm{p}=0.0007)$ [Figure 1].

No correlation was found between the FACIT Sp-12 faith with UCT $(\mathrm{r}=0.055 ; \mathrm{p}=0.58)$ [Figure 2], neither with CU-Q2oL $(\mathrm{r}=-0.113 ; \mathrm{p}=0.26)$.

There was a significant strong inverse correlation between the CU-Q2oL and the UCT $(\mathrm{r}=-0.762 ; \mathrm{p}<0.0001)$ [Figure 3].

\section{Discussion:}

To the best of our knowledge, this is the first study to assess spiritual well-being in subjects with CU. We found that subjects with not controlled CU appeared to experience spiritual well-being on a level worst to that of those with controlled CU. Shenefelt \& Shenefelt suggest that reactions to skin disorders have had and continue to have extensive spiritual aspects. They mention modern understandings of skin disorders and how to treat them have brought important advances, but in fact, healing of the skin continues to have a spiritual aspect and sometimes even today healing is hindered until the spiritual aspect is adequately addressed. ${ }^{22}$

Our study measured QoL and SpWB concurrently. We found that not controlled CU subjects present negatively associated with SpWB and QoL. This is in accordance with recent research which mostly demonstrated emotional distress affect $\mathrm{CU}$ and other skin disease patients QoL, leading them to have a low SpWB. ${ }^{9,} 23-24$ Therefore, providing spiritual care might improve QoL among such patients. 
As well as Brady et al study on the evaluation of spirituality impact in quality of life of oncology patients we found that the faith subscale evidenced significantly smaller correlations with QoL than did the meaning/peace subscale. ${ }^{25}$ Meaning/ Peace was the best predictor of QoL in the CU patients' evaluated.

In line with the UCT development study there was a strong correlation between UCT scores and CU-Q2oL. ${ }^{12}$ In this study we found that UCT scores didn't well correlate with FACIT-Sp-12 subscales, indicating that SpWB were not associated with CU patients' control status.

Current literature suggests several potential interventions intended to help individuals engage in positive spiritual coping. Life review has been suggested as a potential intervention. This intervention is targeted at helping individuals work through the meaning-making process to achieve a positive view of past and present life events. ${ }^{26}$

The literature indicates some patient-generated suggestions for interventions. Regarding spiritually related needs, they suggested provider home visits, visits from volunteers, and that health care providers should generally offer a supporting attitude. ${ }^{27}$

\section{Conclusion:}

Spirituality as marked by the meaning of self and inner independence cooperates with the affective states to determine the QoL of patients with CU. Considering patients' spiritual concerns in the clinical setting is critical in enhancing QoL. No study has ever investigated the role of spirituality in managing patients with urticaria.

Our findings support the impact of poorly controlled urticaria in SpWB and QoL. For many patients, spiritual, existential, or religious beliefs can affect their understanding of illness and can influence treatment decisions. Therefore, clinicians should pay more attention to spirituality among CU patients. We suggest that urticaria guidelines should include specific recommendations on spirituality assessment.

\section{References:}

1. Zuberbier T, Aberer W, Asero R, Abdul Latiff AH, Baker D, Ballmer-Weber B, et al. The EAACI/GA(2)LEN/EDF/WAO guideline for the definition, classification, diagnosis and management of urticaria. The 2017 revision and update. Allergy. 2018;73(7):1393-414.

2. Maurer M, Abuzakouk M, Berard F, Canonica W, Oude Elberink H, Gimenez-Arnau A et al. The burden of chronic spontaneous urticaria is substantial: Real-world evidence from ASSURE-CSU. Allergy. 2017;72(12):2005-2016.

3. Buss YA, Garrelfs UC, Sticherling M. Chronic urticaria-which clinical parameters are pathogenetically relevant? A retrospective investigation of 339 patients. J Dtsch Dermatol Ges. 2007;5(1):22-9.

4. Curto-Barredo L, Riba Archilla L, Roura Vives G, Pujol RM, Gimenez-Arnau AM. Clinical features of chronic spontaneous urticaria that predict disease prognosis and refractoriness to standard treatment. Acta Derm Venereol. 2018;98(7):641-7.

5. Maurer M, Ortonne JP, Zuberbier T. Chronic urticaria: a patient survey of quality-of-life, treatment usage and doctor-patient relation. Allergy. 2009;64(4):581-8.

6. Vietri J, Turner SJ, Tian H, Isherwood G, Balp MM, Gabriel S. Effect of chronic urticaria on US patients: analysis of the National Health and wellness survey. Ann Allergy Asthma Immunol. 2015;115(4):306-11.

7. Dias GAC, Pires GV, Valle SOR, Dortas Junior SD, Levy S, Franca AT, Baiardini I, Canonica WG. Impact of chronic urticaria on the quality of life in universitary hospital's patients. An Bras Dermatol. 2016;91(6):754-9.

8. Maurer M, Staubach P, Raap U, Richter-Huhn G, Bauer A, Rueff F, et al. H1-antihistamine-refractory chronic spontaneous urticaria: it's worse than we thought - first results of the multicenter real-life AWARE study. Clin Exp Allergy. 2017;47(5):684-92.

9. Balp MM, Lopes da Silva N, Vietri J, Tian H, Ensina LF. The Burden of Chronic Urticaria from Brazilian Patients' Perspective. Dermatol Ther (Heidelb). 2017Dec;7(4):535-545. 
10. Itakura A, Tani Y, Kaneko N, Hide M. Impact of chronic urticaria on quality of life and work in Japan: Results of a real-world study. Journal of Dermatology 2018; 45: 963-970.

11. Valle SOR, Dortas-Junior SD, Dias GAC, Motta AA, Falcao-Amaral CS, Martins EAPR, et al. Ferramentas para avaliacao e acompanhamento da urticaria cronica. Braz J Allergy Immunol. 2018;2(2):209224

12. Weller K, Groffik A, Church MK, Hawro T, Krause K, Metz M, et al. Development and validation of the urticaria control test: a patient-reported outcome instrument for assessing urticaria control. J Allergy Clin Immunol. 2014; 133:1365-1372, 1372.e1-6.

13. Baiardini I1, Pasquali M, Braido F, Fumagalli F, Guerra L, Compalati E, et al. A new tool to evaluate the impact of chronic urticaria on quality: chronic urticaria quality of life questionnaire (CU-Q2oL). Allergy. 2005; 60:1073-8.

14. Dias GA, Pires GV, Valle SO, Franca AT, Papi JA, Dortas SD Jr, et al. Cross-cultural adaptation of the Brazilian-Portuguese version of the chronic urticaria quality-of life questionnaire - CU-Q2oL. Allergy. 2011; 66:1487-93.

15. Dortas Junior SD, Valle SOR, Weller K, Maurer M, Lupi O. Validity, reliability, and interpretability of the Brazilian urticaria control test. Allergy Asthma Proc 41:1-6, 2020.

16. Fitchett G, Peterman AH, Cella DF: Spiritual beliefs and quality of life in cancer and HIV patients. Paper presented at: The Society for Scientific Study of Religion, Nashville, Tennessee, 1996.

17. VanderWeele TJ, Balboni TA, Koh HK. Health and Spirituality. JAMA. 2017 Aug 8;318(6):519-520.

18. Maurer M, Metz M, Bindslev-Jensen C, Bousquet J, Canonica GW, Church MK, et al. Definition, aims, and implementation of GA(2)LEN urticaria centers of reference and excellence. Allergy. 2016; 71:1210-1218.

19. Cella DF, Tulsky DS, Gray G, Sarafian B, Linn E, Bonomi A, et al. The Functional Assessment of Cancer Therapy scale: development and validation of the general measure. J Clin Oncol 1993;11(3):570579 .

20. Peterman, A.H., Fitchett, G., Brady, M.J., et al. (2002). Measuring spiritual well-being in people with cancer: The Functional Assessment of Chronic Illness Therapy-Spiritual Well-Being Scale (FACIT-Sp). Annals of Behavioral Medicine, 24, 49-58.

21. Lucchetti G, Lucchetti AL, de Bernardin Goncalves JP, Vallada HP. Validation of the Portuguese version of the Functional Assessment of Chronic Illness Therapy-Spiritual Well-Being scale (FACIT-Sp 12) among Brazilian psychiatric inpatients. J Relig Health. 2015 Feb;54(1):112-21.

22. Shenefelt PD, Shenefelt DA. Spiritual and religious aspects of skin and skin disorders. Psychol Res Behav Manag. 2014;7:201-212.

23. Choi GS, Nam YH, Park CS, Kim MY, Jo EJ, Park HK, et al. Anxiety, depression, and stress in Korean patients with chronic urticaria [published online ahead of print, 2020 May 27]. Korean J Intern Med. 2020;10.3904/kjim.2019.320.

24. Unterrainer HF, Lukanz M, Pilch M, et al. The influence of religious/spiritual well-being on quality of life in dermatological disease. Br J Dermatol. 2016;174(6):1380-1383.

25. Brady MJ, Peterman AH, Fitchett G, Mo M, Cella D. A case for including spirituality in quality of life measurement in oncology. Psychooncology. 1999;8(5):417-428.

26. Steinhauser KE, Alexander SC, Byock IR, George LK, Olsen MK, Tulsky JA. Do preparation and life completion discussions improve functioning and quality of life in seriously ill patients? Pilot randomized control trial. J Palliat Med. 2008;11(9):1234-1240.

27. Ross L, Austin J. Spiritual needs and spiritual support preferences of people with end-stage heart failure and their carers: implications for nurse managers. J Nurs Manag. 2015;23(1):87-95.

Table 1 - Patient sample characteristics

\begin{tabular}{ll}
\hline $\mathbf{n}$ of patients & 100 \\
Gender & \\
Females (n of patients) & 82 \\
Males (n of patients) & 18
\end{tabular}




\begin{tabular}{ll} 
Age, \pm SD (range), $\mathbf{y}$ & $43 \pm 15,(13-78)$ \\
Form of Chronic Urticaria & \\
CSU (n of patients) & 51 \\
CSU + CIndU (n of patients) & 40 \\
CIndU (n of patients) & 9 \\
Angioedema (n of patients) & 65 \\
\hline
\end{tabular}

\section{$S D=$ Standard deviation; $C S U=$ chronic spontaneous urticaria; CIndU = chronic inducible urticaria}

Table 2 - Score sample characteristics

\begin{tabular}{llllll}
\hline Scores & $\mathbf{n}$ & mean & SD & median & IQR \\
\hline TOTAL & & & & & \\
Facit Sp-12 meaning/peace & 100 & 21,6 & 4,9 & 21,5 & $18-24$ \\
Facit Sp-12 faith & 100 & 13,1 & 3,1 & 14 & $12-16$ \\
CU-Q2oL & 100 & 46,8 & 19,9 & 44 & $28-58$ \\
UCT & 100 & 10,9 & 4,7 & 12 & $8-15$ \\
UCT $<\mathbf{1 2}$ & $\mathbf{U C T}<\mathbf{1 2}$ & $\mathbf{U C T}<\mathbf{1 2}$ & $\mathbf{U C T}<\mathbf{1 2}$ & $\mathbf{U C T}<\mathbf{1 2}$ & $\mathbf{U C T}<\mathbf{1 2}$ \\
Facit Sp-12 meaning/peace & 45 & 20,0 & 5,0 & 19 & $17,5-24$ \\
Facit Sp-12 faith & 45 & 12,7 & 3,5 & 14 & $10-16$ \\
CU-Q2oL & 45 & 62,1 & 17,8 & 58 & $51-75$ \\
UCT & 45 & 6,8 & 3,7 & 8 & $4-11$ \\
UCT[?]12 & $\mathbf{U C T}[?] \mathbf{1 2}$ & $\mathbf{U C T}[\mathbf{?}] \mathbf{1 2}$ & $\mathbf{U C T}[\mathbf{?}] \mathbf{1 2}$ & $\mathbf{U C T}[\mathbf{?}] \mathbf{1 2}$ & $\mathbf{U C T}[?] \mathbf{1 2}$ \\
Facit Sp-12 meaning/peace & 55 & 22,9 & 4,4 & 23 & $19-25$ \\
Facit Sp-12 faith & 55 & 13,4 & 2,7 & 14 & $12-16$ \\
CU-Q2oL & 55 & 34,3 & 10,7 & 31 & $26-41$ \\
UCT & 55 & 14,3 & 1,6 & 14 & $13-16$ \\
\hline
\end{tabular}

$S D=$ Standard deviation; $I Q R=$ interquartile range

Figure 1 - FACIT Sp-12 Meaning/Peace correlation to UCT

Figure 2 - FACIT Sp-12 Faith correlation to UCT

Figure 3 - CU-Q2oL correlation to UCT

Hosted file

Figure 1 - FACIT Sp-12 MeaningPeace correlation to UCT.ppt available at https://authorea.com/ users/360764/articles/482296-spiritual-well-being-and-quality-of-life-are-impaired-inchronic-urticaria

\section{Hosted file}

Figure 2 - FACIT Sp-12 Faith correlation to UCT.ppt available at https://authorea.com/users/ 360764/articles/482296-spiritual-well-being-and-quality-of-life-are-impaired-in-chronicurticaria

\section{Hosted file}

Figure 3 -- CU-Q2oL correlation to UCT.ppt available at https://authorea.com/users/360764/ articles/482296-spiritual-well-being-and-quality-of-life-are-impaired-in-chronic- 
urticaria 